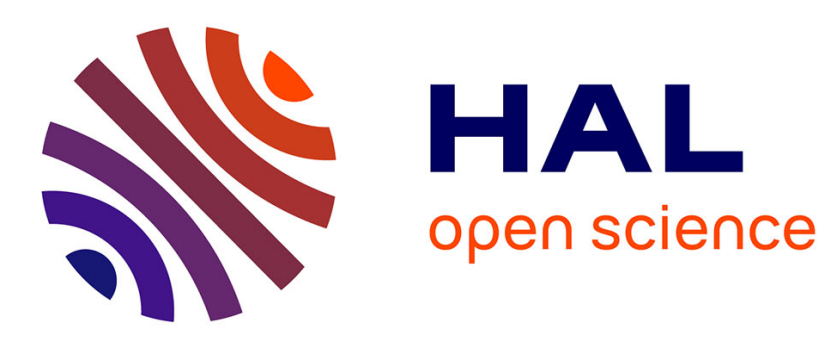

\title{
The effect of re-employment on perceived health
}

Merel Schuring, Johan P Mackenbach, Toon Aj Voorham, Alex Burdorf

\section{To cite this version:}

Merel Schuring, Johan P Mackenbach, Toon Aj Voorham, Alex Burdorf. The effect of re-employment on perceived health. Journal of Epidemiology and Community Health, 2010, 65 (7), pp.639. 10.1136/jech.2009.103838 . hal-00600745

\section{HAL Id: hal-00600745 https://hal.science/hal-00600745}

Submitted on 16 Jun 2011

HAL is a multi-disciplinary open access archive for the deposit and dissemination of scientific research documents, whether they are published or not. The documents may come from teaching and research institutions in France or abroad, or from public or private research centers.
L'archive ouverte pluridisciplinaire HAL, est destinée au dépôt et à la diffusion de documents scientifiques de niveau recherche, publiés ou non, émanant des établissements d'enseignement et de recherche français ou étrangers, des laboratoires publics ou privés. 


\section{The effect of re-employment on perceived health}

Merel Schuring ${ }^{1}$, Johan Mackenbach ${ }^{1}$, Toon Voorham ${ }^{2}$, Alex Burdorf $^{1}$

1 Department of Public Health, Erasmus MC, Rotterdam, The Netherlands

2 Municipal Health Service GGD Rotterdam, Rotterdam, The Netherlands

Correspondence address:

Alex Burdorf, $\mathrm{PhD}$

Department of Public Health

Erasmus MC

PO Box 2040

3000 CA Rotterdam

The Netherlands

Fax: +31-10-7030045

E-mail: a.burdorf@erasmusmc.nl

Word count: 3.601 


\begin{abstract}
Background: The relationship between unemployment and poor health has been well established. Unemployment causes poor health and poor health increases the probability of unemployment.

Methods: A prospective study with 6 months follow-up was conducted among unemployed subjects receiving social security benefits, who were capable of full time employment and were referred to a re-employment training centre. Re-employment was defined as ending social security benefits for at least three months because of starting with paid employment. Health related quality of life was measured by the Short Form 36 Health Survey (SF-36). A Cox Proportional Hazards analysis was used to determine the factors that predicted reemployment during follow-up. The influence of re-employment on changes in perceived health was investigated with linear regression analysis.

Results: Unemployed subjects with a poor health at baseline were less likely to return to paid employment during follow-up. Almost all dimensions of health at baseline had an influence on the likelihood of becoming employed. Among the re-employed subjects, general health, physical functioning, social functioning, vitality, mental health, bodily pain, and role-limitations due to emotional or physical problems improved, with an effect size varying from 0.11 to 0.66 .

Conclusion: This study provides evidence that re-employment leads to improvement of self-perceived health within a short time window. This suggests that labour force participation should be considered as therapeutic intervention within health promotion programmes among unemployed persons.
\end{abstract}




\section{INTRODUCTION}

The relationship between unemployment and poor health has been well established, as demonstrated by a higher prevalence of illness and disability ${ }^{1,2}$ and a higher mortality among unemployed people. ${ }^{3}$ The association between health and employment is bidirectional: unemployment may cause poor health (causation hypothesis), and poor health may increase the probability of unemployment (selection hypothesis).

There is evidence for the selection hypothesis. A longitudinal study among European countries showed that in the majority of European countries a perceived poor health or a chronic health problem predicted becoming or staying unemployed. ${ }^{4}$ A community based survey in the United Kingdom found that health related job loss had become increasingly common, especially in relation to musculoskeletal disorders and mental illness. ${ }^{5}$ A twoyear follow up study of long term unemployed Norwegians reported that health related selection to long term unemployment explained a substantial part of the excess mental morbidity among unemployed people. ${ }^{6}$

However, there is also evidence for the causation hypothesis. Various studies have shown that unemployment gave rise to health effects, especially psychological distress, depression, and reduced mental health. A review of 16 longitudinal studies concerning mental health effect of unemployment concluded that loss of employment affected mental health, but also that gaining employment improved mental health. ${ }^{7}$ A British longitudinal study found that transitions from paid employment to various forms of non-employment (unemployment, long-term sick leave, maternity leave) had a negative impact on mental health. Transitions from non-employment to formal employment resulted in an improvement of mental health. The effects were felt most strongly within six months after the transition. ${ }^{8}$ A five-year follow up study among long-term unemployed Norwegians reported recovery of mental health after re-employment. ${ }^{9}$

"Work, matched to one's knowledge and skills and undertaken in a safe, healthy environment, can reverse the harmful effects of prolonged sickness absence or long term unemployment, and promote health, well-being and prosperity". This is the main message of the so-called Black report, which reviewed the health of Britain's working-age population $^{10,11}$ In a review Waddel and Burton ${ }^{12}$ concluded that re-employment leads to clear benefits in psychological health and some measures of well-being, although there is a dearth of information on physical health. A meta-analytic study of the psychological and physical well-being during unemployment also demonstrated that the bulk of research is 
focused on mental health outcomes, suggesting that other aspects of health need more attention. ${ }^{13}$ One study on re-employment indicated that physical as well as mental health improved among those working at one year follow-up compared to those not working. ${ }^{14}$ Another study also showed a positive association between gaining employment and physical functioning among older workers who were displaced. ${ }^{15}$ However, both studies were among older workers who were recently displaced or early retired. It is not known whether these results can be generalized to the whole working age population with a different unemployment history.

The impact of re-employment on mental health is reported by two meta-analytic studies. ${ }^{7,13}$ There is limited insight into the effect size of re-employment on other dimensions of health. ${ }^{13}$ The aim of this study was to investigate the effect of reemployment on different dimensions of health within a short period after entering paid employment. 


\section{METHODS}

\section{Study population}

A prospective study with 6 months follow-up was conducted among unemployed subjects. The study population consisted of persons on social security benefits who were capable of full time employment and who were referred by the Employment Centre of the City of Rotterdam, The Netherlands, to one of the four re-employment training centres in the area for a re-employment training. Some of the participants did have chronic health problems, but were declared fit enough to be capable of full time employment after investigation by a physician, a psychologist, and an employment specialist. From December 2004 until December 2007, every week an average of 19 subjects was enrolled in the study after referral to a re-employment training centre. In total, 2754 eligible participants were included in the study. Participation in this study was voluntary. The Medical Ethics Committee of Erasmus MC provided a declaration of no objection.

\section{Data collection}

The first questionnaire was sent to prospective participants immediately after the referral to the re-employment training centre. The follow-up questionnaire was sent six months later. The procedure of data collection was similar at baseline and follow-up. The first questionnaire was sent to the home address of the participants, followed by two reminders two respectively four weeks later. Additional actions were undertaken to include more subjects. As a large part of the study population had a non-Dutch background, the questionnaire and covering letter were translated in Turkish and send in addition to the Dutch questionnaire to subjects with a Turkish surname. If subjects of the study population needed help with filling in the questionnaire, they could get in touch with an interviewer. Subjects who did not reply to the postal questionnaire were visited by an interviewer at their home address with four attempts at different day times during a two week period. The interviewers were matched with the subjects, based on ethnicity, age, and gender, and could offer an interview in the mother tongue (Dutch, Arabic, or Turkish).

\section{Socio-demographic variables}

Socio-demographic variables, such as ethnic background, highest educational level, age, sex, and marital status were included in the questionnaire. Ethnic background of the respondent was based on the country of birth of the mother. In case the mother was born in 
The Netherlands, the country of birth of the father was leading. ${ }^{16}$ Different ethnic groups were defined, based on differences in geographical and cultural distance from the Netherlands. Three ethnic minority groups were defined: 1) Turks and Moroccans, 2) Antilleans and Surinamese, and 3) a miscellaneous group with all other countries of origin. Subjects were divided into three groups according to their highest level of educational attainment. A high educational level was defined as higher vocational training or university, intermediate educational level was defined as higher secondary schooling or intermediate vocational training, and low educational level was defined as no education, primary school, lower and intermediate secondary schooling or lower vocational training. Marital status was used to distinguish those subjects married or living together from others.

\section{Psychological measures}

Mastery was measured by the Personal Mastery Scale ${ }^{17}$, which consists of seven items (eg "I have little control over the things that happen to me", "There is little I can do to change many of the important things in my life"), answered on a four point Likert scale (strongly agree to strongly disagree). Average scores across items were calculated, ranging from 1 to 4 , with a higher score indicating a higher level of mastery. In case three or more items were unanswered, no score was computed.

Self-esteem was measured with the Rosenberg Self-Esteem Scale ${ }^{18}$, with 10 items (e.g., "On the whole, I am satisfied with myself", "All in all, I am inclined to feel that I am a failure"), answered on a four point Likert scale (strongly agree to strongly disagree). Average scores across items were calculated again, ranging from 1 to 4; a higher score indicated a higher level of self-esteem. In case three or more items were unanswered, no score was computed.

\section{Re-employment training}

A re-employment training centre provided a standardized approach of a re-employment training, characterized by a broad re-orientation on employment and employability, enhancement of job search skills, and intensification of job search efforts.

\section{Re-employment}

Start and end dates of the social security benefits were registered at the Employment Centre of the City of Rotterdam, The Netherlands. In these registers, additional information about reasons for ending benefits was also administered. Re-employment was 
defined as leaving the social security benefit services for at least three months because of starting with paid employment, verified by the national Social Security Agency. Subjects who quitted their registration for a social security benefit for other reasons, for example moving in with a partner or moving out of the city of Rotterdam, were censored from the moment that their benefit payment was quitted by the social security services.

\section{Health measures}

Health related quality of life was measured with the Dutch version of the Short Form 36

Health Survey (SF-36). ${ }^{19,20}$ Self-reported health (SRH) was measured with the first item of the SF-36 by asking subjects to rate their overall health on a five-point scale, ranging from 'excellent', very good', 'good' and 'fair' to 'poor'. Those reporting less than 'good health' were defined as having a poor health. ${ }^{21}$

The other 35 items of the SF-36 were used to calculate scores on eight dimensions: physical functioning, general health, mental health, bodily pain, social functioning, vitality, role limitation due to emotional health problems, and role limitation due to physical health problems. Scores could range from 0 to 100 , with a higher score indicating a better health related quality of life.

\section{Statistical analysis}

All statistical analyses were conducted by means of the statistical package SPSS (version 15) for Windows and the level of significance was set at 0.05 .

In the analyses two groups of respondents were compared, those who were still unemployed at follow-up and those who were re-employed at follow-up. The baseline characteristics of both groups were compared with the chi-square test for dichotomous data and the t-test for continuous data. Non-response to the first questionnaire and loss-tofollow up during the six months until the second questionnaire were investigated by logistic regression analysis with potential determinants; individual characteristics, perceived health, participation in re-employment training, and re-employment.

A Cox Proportional Hazards analysis was used to determine the factors that predicted re-employment during the follow-up period. The follow-up period was censored at date of re-employment. Independent factors were individual characteristics, self esteem, mastery, and the eight dimensions of the SF36. Variables were coded in such a manner that a Hazard Ratio above 1 indicates an increased likelihood of re-entering paid employment. For each dimension of the SF36 a standardized Hazard Ratio was calculated based on an 
average score across items, representing the effect of an increase of one standard deviation in the average score at baseline on the likelihood of entering paid employment. Individual characteristics with a significant univariate effect on re-employment, were entered first in the multivariate model. Subsequently, the health measure with the largest goodness-of-fit in the univariate analysis was entered in the multivariate model. After that, the effect of the other measures of health were investigated for their additional effect on goodness-of-fit.

The association of re-employment with changes in perceived health was investigated with linear regression analysis. The association of re-employment with each dimension of health was adjusted for age, sex, ethnic background, education, duration on benefit, participation in a re-employment training, and also for the baseline value of the health dimension under study. For each dimension of health Cohen's d was calculated as measure of effect size by dividing the difference in health before and after re-employment by their pooled standard deviation. ${ }^{22}$ 


\section{RESULTS}

Figure 1 shows that 2754 subjects were enrolled in the study after referral to a reemployment training centre. One third of the subjects $(n=932)$ had chronic health complaints, but were declared to be fit enough to be capable of full time employment after investigation by a physician, a psychologist and an employment specialist. From the 2754 subjects who received the first questionnaire, 1829 subjects (66\%) filled out and returned the questionnaire. More than two third of the respondents (70\%) returned the baseline questionnaire by post, whereas almost one third of the respondents (30\%) had a face-toface interview. Non-response was statistically significantly higher among younger subjects and men.

The response at follow-up was 53\% (965/1829). Loss-to-follow up was statistically significantly higher among younger subjects, men, and subjects of non-Dutch origin, but not related to marital status, employment history, duration on benefit, or health at baseline. Subjects who had started with a re-employment training $(n=461)$ were less often lost to follow up (OR=0.8, 95\% CI 0.7-1.0), whereas subjects who had returned to paid employment $(\mathrm{n}=123)$ were more often lost to follow up ( $\mathrm{OR}=1.9,95 \%$ CI 1.3-2.7). However, among those who returned to paid employment, health at baseline did not differ significantly between non-respondents $(n=76)$ and respondents $(n=47)$ at follow-up.

Table 1 shows the characteristics of the respondents to the first questionnaire. The mean age of respondents was 39.7 (sd 9.5) years, $49 \%$ was man, 57\% had a low level of education, $75 \%$ belonged to an ethnic minority group, and $43 \%$ received social security benefits for more than five years. During the follow-up period $30 \%$ of the respondents had started with a re-employment training. 
Table 1 Characteristics of respondents to the first questionnaire $(n=1829)$

\begin{tabular}{|c|c|}
\hline Variable & $\begin{array}{l}\text { Respondents } \\
\mathrm{N}=1829\end{array}$ \\
\hline \multicolumn{2}{|l|}{ Age $(\mathrm{n}-\%)$} \\
\hline $18-44 \mathrm{yr}$ & $1230(67)$ \\
\hline $45-64 \mathrm{yr}$ & $599(33)$ \\
\hline Men $(\mathrm{n}-\%)$ & $894(49)$ \\
\hline Marital status living with partner (n-\%) & $601(33)$ \\
\hline \multicolumn{2}{|l|}{ Educational level (n - \%) } \\
\hline Higher and intermediate level & $634(35)$ \\
\hline Lower level & $1049(57)$ \\
\hline Missing & $146(8)$ \\
\hline \multicolumn{2}{|l|}{ Ethnic background (n - \%) } \\
\hline Native Dutch & $450(25)$ \\
\hline Turkish / Moroccan & $448(25)$ \\
\hline Antillean / Surinamese & $488(27)$ \\
\hline Refugee / Other immigrants & $404(23)$ \\
\hline \multicolumn{2}{|l|}{ Duration on social benefit $(\mathrm{n}-\%)$} \\
\hline Less than one year & $478(27)$ \\
\hline Between 1 and 5 years & $512(29)$ \\
\hline 5 years and more & $759(43)$ \\
\hline Started with re-employment training $(\mathrm{n}-\%)$ & $541(30)$ \\
\hline Self esteem (scale 1-4: mean - sd) & $2.48(0.6)$ \\
\hline Mastery (scale 1-4: mean - sd) & $2.89(0.5)$ \\
\hline
\end{tabular}

Figure 2 shows that health at baseline was better among subjects who returned to paid employment during the follow-up period. All dimensions of health improved among re-employed subjects, whereas the health status of unemployed subjects remained unchanged.

Table 2 shows that unemployed subjects with a poor health at baseline were less likely to return to paid employment during follow-up ( $\mathrm{OR}=0.39,95 \%$ CI 0.2-0.7). All dimensions of perceived health at baseline had an influence on the likelihood of becoming employed, except for mental health. Physical functioning had the strongest influence on the likelihood of becoming employed ( $\mathrm{OR}=2.76,95 \%$ 1.8-4.3). Ethnic background, marital 
status, self esteem, mastery, and participating in a re-employment training were not significant in the univariate model.

Table 2 The influence of individual characteristics and dimensions of self-perceived health among long-term unemployed persons $(n=965)$ on the likelihood of re-employment $(\mathrm{n}=47)$ during a follow-up period of six months.

(Cox Proportional Hazards analysis)

\begin{tabular}{|c|c|c|}
\hline & $\begin{array}{l}\text { Re-employment } \\
\text { (univariate model) }\end{array}$ & $\begin{array}{l}\text { Re-employment } \\
\text { (multivariate model) }\end{array}$ \\
\hline & Hazard Ratio (95\%CI) & Hazard Ratio $(95 \% \mathrm{CI})$ \\
\hline Higher age ( $>45$ years) & $0.40(0.20-0.83)^{* *}$ & $0.45(0.19-1.10)^{*}$ \\
\hline Men & $2.19(1.21-3.97)^{* *}$ & $1.74(0.91-3.31)$ \\
\hline Low educational level & $0.52(0.30-0.93)^{* *}$ & $0.60(0.32-1.12)$ \\
\hline Poor health & $0.39(0.22-0.69)^{* *}$ & - \\
\hline General health $^{\top}$ & $1.57(1.20-2.07)^{* *}$ & - \\
\hline Physical functioning $^{1}$ & $2.76(1.80-4.24)^{* *}$ & $2.18(1.40-3.38)^{* *}$ \\
\hline Bodily pain $^{1}$ & $1.92(1.42-2.60)^{* * *}$ & - \\
\hline Mental health $^{1}$ & $1.19(0.89-1.59)$ & - \\
\hline Social functioning $^{1}$ & $1.54(1.13-2.10)^{* *}$ & - \\
\hline Vitality $^{1}$ & $1.48(1.12-1.95)^{* *}$ & - \\
\hline Role functioning, emotional ${ }^{1}$ & $1.44(1.06-1.96)^{* *}$ & - \\
\hline Role functioning, physical $^{\top}$ & $1.72(1.25-2.37)^{* *}$ & - \\
\hline
\end{tabular}

$* * \mathrm{p}<0.05, * \mathrm{p}<0.10$

1 Standardized Hazard Ratio, representing the effect of an increase of one standard deviation in the average score.

In the multivariate analysis, physical functioning at baseline had the strongest association with re-employment. Due to the correlations of the other health measures with physical health (general health $r=0.56$, bodily pain $r=0.62$, mental health $r=0.26$, social functioning $r=0.43$, vitality $r=0.41$, role functioning, emotional $r=0.27$, role functioning, physical $r=0.55$ ), these measures of health did not have a significant contribution to the multivariate model including physical functioning. 
Table 3 shows that among the re-employed subjects general health, physical functioning, social functioning, vitality, mental health, bodily pain, and role-limitations due to emotional or physical problems improved during the follow-up period, with an effect size varying from 0.11 to 0.66 . The largest relative improvements were observed for mental health, social functioning, and role-limitations due to emotional or physical problems, whereas physical functioning showed the smallest relative improvement. For those subjects who remained unemployed the effect sizes varied from -0.04 to 0.06 , indicating that their health status remained virtually unchanged during the six months follow-up period. Participation in a re-employment training was not associated with change of health status (data not shown).

Table 3: The influence of re-employment on changes in eight dimensions of health measured by the SF-36 health questionnaire among long-term unemployed persons during a follow-up period of six months.

\begin{tabular}{|l|c|c|}
\hline & $\begin{array}{l}\text { Effect of re-employment } \\
\text { change }(\mathrm{SE}) \\
(\mathrm{n}=965)\end{array}$ & $\begin{array}{l}\text { Effect size }^{2} \\
(\text { Cohen's d) } \\
(\mathrm{n}=47)\end{array}$ \\
\hline General health & $+7.0(2.7)^{* *}$ & +0.18 \\
\hline Physical functioning & $+11.3(3.6)^{* *}$ & +0.11 \\
\hline Bodily pain & $+11.0(2.7)^{* *}$ & +0.20 \\
\hline Mental health & $+14.2(3.8)^{* *}$ & +0.32 \\
\hline Social functioning & $+7.8(2.5)^{* *}$ & +0.26 \\
\hline Vitality & $+22.7(6.8)^{* *}$ & +0.46 \\
\hline Role functioning, emotional & $+20.0(6.0)^{* *}$ & +0.33 \\
\hline Role functioning, physical &
\end{tabular}

1. Each linear regression model was adjusted for age, gender, ethnic background, education, duration on benefit, and health at baseline.

2: Effect sizes were based on the mean values of health at baseline and follow-up of the re-employed subjects 


\section{DISCUSSION}

Unemployed subjects with a poor health at baseline were less likely to return to paid employment during follow-up. Almost all dimensions of health at baseline had an influence on the likelihood of becoming employed. The strongest association was found between physical functioning at baseline and re-employment. Among the re-employed subjects, general health, physical functioning, social functioning, vitality, mental health, bodily pain, and role-limitations due to emotional or physical problems improved, with an effect size varying from 0.11 to 0.66 . Hence, re-employment positively influenced mental health as well as physical health.

Loss to follow up was significantly higher among younger subjects, men, subjects of non-Dutch origin and subjects who had returned to paid employment. However, among those who found employment $(n=123)$, health at baseline did not differ between nonrespondents $(n=76)$ and respondents $(n=47)$ at follow up. Therefore, we assume that the effects of re-employment on health were not influenced by selective loss to follow up.

Subjects who were referred to a re-employment training centre were included in the study. The policy of the Employment Centre of the City of Rotterdam was to refer everybody who was able to work and could use some help with searching for a job. Hence, subjects were not included in the study when they were not able (due to health problems) or not obliged (due to family obligations or education) to work. In addition, recently unemployed persons who were supposed to be able to find paid employment by themselves, were not included. This may have affected the results with respect to health status and re-employment probabilities.

The re-employed workers got their jobs at different times during the follow-up period of the study. Therefore, some persons may have been back at work for much longer than others and thus, the length of exposure to the health benefits of re-employment varied amongst the re-employed sample. Unfortunately, due to the small number of persons who gained employment it is not feasible to analyse the relation between time at work and health benefits due to re-employment.

The study is based on self-reported health status. Therefore, justification bias may have influenced the present results. Respondents who were still unemployed at follow up may have reported more easily that they had a poor health than those who found paid employment in order to justify the fact that they did not find a job. ${ }^{23}$ 
Due to the observational design of the study the results may have been influenced by selection bias. Subjects who found employment differed from those who stayed unemployed with respect to health at baseline and personal characteristics. These variables were adjusted for in the analysis, but there may have been other variables that influenced both health change and re-employment, e.g. motivation to work, that were not included in the analysis. However, two psychological measures that were included in the study, self esteem and mastery, did not have a significant influence on the likelihood of reemployment. In addition, these psychological measures did not influence the estimated effects of re-employment on health.

To control for the systematic differences in health at baseline between the unemployed and re-employed subjects, stratified analyses were conducted showing that reemployment resulted in an increase of health for both subjects with a poor health at baseline as well as subjects with a good health at baseline. In general, subjects with a poor health at baseline showed a larger increase in health after re-employment than subjects with a good health at baseline (data not shown).However, after finding paid employment the health status of recently re-employed subjects still lagged the health status of long-term employed persons. ${ }^{24}$

Unemployed subjects with a good health were more likely to return to paid employment during follow-up. Therefore, the results of this study support the selection hypothesis. These findings are in accordance with a study of the European Community Household Panel, which found that a poor health or chronic health problem predicted staying or becoming unemployed in European countries. ${ }^{4}$ A two year follow up study of long term unemployed in Norway showed that health related selection to long term unemployment explained a substantial part of the excess mental morbidity among unemployed people. ${ }^{6}$

This study also showed that the health status of re-employed subjects improved, whereas the health status of unemployed subjects remained unchanged. Re-employment did not only have a positive influence on mental health, but also on physical functioning, which was in accordance with findings from two other studies ${ }^{14,15}$ Based on these finding, it seems most likely that starting with paid employment results in health improvement. However, due to the design of the study it cannot be ruled out that it is the other way around; a change in health status may increase the likelihood of finding paid employment. However, a review showed that an increase in health status of long term unemployed is rather unlikely. ${ }^{2}$ Therefore, it is assumed that the health status of participants increased 
shortly after re-employment, supporting the causation hypothesis. This is in congruence with findings from other studies, which found an increase in mental health status after reemployment. $^{8,9}$

In the present study, an effect size of 0.66 was found for the improvement of mental health after re-employment. This result is in accordance with findings from two metaanalytic studies $^{7,13}$, reporting that gaining employment impacts on mental health with an effect size of 0.54 respectively 0.89 . The effects on other dimensions were slightly lower, but since different dimensions of health were associated with each other it is difficult to infer that mental health seems more important than physical health. This is in accordance with the results of the Whitehall II study of civil servants, which showed that physical and mental health were correlated for participants with a low socioeconomic position. ${ }^{25}$

In the current study only $5 \%$ (47/965) of the participants found paid employment within six months. This low re-employment rate is in accordance with a study among persons receiving social security benefits in the city of Amsterdam, the Netherlands, which showed that only $8 \%$ of the persons found paid employment in a two-year period from 2004-2006. ${ }^{26}$ The current study population is characterised by a long-term unemployment history. Long-term unemployed subjects often have much difficulty in finding paid employment, especially for those with a poor health. All participants in the study were referred to a re-employment training centre for a re-employment training. However, this reemployment training did not have a positive effect on the probability of re-employment or on the health status of participants. Therefore, other measures seem to be required to increase the chance of re-employment for long term unemployed with a poor health.

In the recent Black report on the health of the British working age population, Black appealed for changing perceptions of fitness for work. Instead of sticking to the idea that one cannot work unless $100 \%$ fit, it is recommended that a campaign should be launched to make employers, healthcare professionals and the general public aware that work is in general good for health. ${ }^{10}$ This study provides evidence that work is indeed good for your health and, thus, work should be considered as an important part of health promotion programmes among unemployed persons. In policies for health equity public health measures are required to include persons with a poor health in the labour market and to prevent workers with ill health from dropping out of the workforce.

\section{Competing interests: None.}




\section{Licence statement}

I (Alex Burdorf), the Corresponding Author of this article (the Contribution) has the right to grant on behalf of all authors and does grant on behalf of all authors, a licence to the BMJ Publishing Group Ltd and its licensees, to permit this Contribution (if accepted) to be published in Journal of Epidemiology and Community Health (JECH) and any other BMJ Group products and to exploit all subsidiary rights, as set out at (http://jech.bmj.com/ifora/licence.pdf).

\section{What is already known on this subject}

- The relationship between unemployment and poor health has been well established.

- Unemployment may cause poor health, and poor health may increase the probability of unemployment.

\section{What does this study add?}

- Among re-employed persons, general health, physical functioning, bodily pain, mental health, social functioning, vitality and role-limitations due to emotional or physical problems improved, with an effect size varying from 0.11 to 0.66 .

- Re-employment leads to improvement of self-perceived health within a short time window.

- Socioeconomic inequalities in health can be reduced by increasing labour participation. 


\section{REFERENCES}

1. Bartley M, Sacker A, Clarke P. Employment status, employment conditions, and limiting illness: prospective evidence from the British household panel survey 1991-2001. Journal of epidemiology and community health 2004;58:501-6.

2. Janlert U. Unemployment as a disease and diseases of the unemployed. Scand $J$ Work Environ Health 1997;23 Suppl 3:79-83.

3. Morris JK, Cook DG, Shaper AG. Loss of employment and mortality. BMJ (Clinical research ed 1994;308:1135-9.

4. Schuring M, Burdorf A, Kunst AE, Mackenbach JP. The effect of ill health on entering and maintaining paid employment: evidence in European countries. Journal of epidemiology and community health 2007;61:597-604.

5. Solomon C, Poole J, Palmer KT, Coggon D. Health-related job loss: findings from a community-based survey. Occup Environ Med 2007;64:144-9.

6. Claussen B, Bjorndal A, Hjort PF. Health and re-employment in a two year follow up of long term unemployed. Journal of epidemiology and community health 1993;47:14-8.

7. Murphy GC, Athanasou, J.A. The effect of unemployment on mental health. Journal of Occupational and Organizational Psychology 1999;72:83-99.

8. Thomas C, Benzeval M, Stansfeld SA. Employment transitions and mental health: an analysis from the British household panel survey. Journal of epidemiology and community health 2005;59:243-9.

9. Claussen B. Health and re-employment in a five-year follow-up of long-term unemployed. Scand J Public Health 1999;27:94-100.

10. Black C. Working for a healthier tomorrow. London: The Stationery Office 2008:ISBN: 9780117025134

11. Hulshof CT. Working for a healthier tomorrow. Occup Environ Med 2009;66:1-2.

12. Waddell G, Burton, A.K. Is work good for your health and well-being? London: The Stationery Office 2006:ISBN:9780117036949.

13. McKee-Ryan F, Song Z, Wanberg CR, Kinicki AJ. Psychological and physical well-being during unemployment: a meta-analytic study. J Appl Psychol 2005;90:53-76.

14. Pattani S, Constantinovici N, Williams S. Predictors of re-employment and quality of life in NHS staff one year after early retirement because of ill health; a national prospective study. Occup Environ Med 2004;61:572-6.

15. Gallo WT, Bradley EH, Siegel M, Kasl SV. Health effects of involuntary job loss among older workers: findings from the health and retirement survey. $J$ Gerontol B Psychol Sci Soc Sci 2000;55:S131-40.

16. CBS. Herkomst van personen; allochtonen en migratie [Country of origin of persons; migrants and migration]. Centraal Bureau voor de Statistiek, Voorburg / Heerlen 2003.

17. Pearlin LI, Schooler C. The structure of coping. J Health Soc Behav 1978;19:2-21.

18. Rosenberg M. Society and the adolescent self-image. Princeton: Princeton University Press 1965.

19. Ware JE, Jr., Sherbourne CD. The MOS 36-item short-form health survey (SF-36). I. Conceptual framework and item selection. Med Care 1992;30:473-83.

20. Van der Zee KI, Sanderman R. Het meten van de algemene gezondheidstoestand met de RAND-36: een handleiding [Measuring health status with the RAND-36: a manual]; 1993. 
21. Fayers PM, Sprangers MA. Understanding self-rated health. Lancet 2002;359:1878.

22. Cohen J. Statistical power analysis for the behavioral sciences (2nd ed.). Hillsdale, NJ: Lawrence Earlbaum Associates 1988.

23. Kapteyn A, Smith JP, van Soest A. Dynamics of work disability and pain. J Health Econ 2008;27:496-509.

24. Schuring M, Burdorf A, Kunst A, Voorham T, Mackenbach J. Ethnic differences in unemployment and ill health. Int Arch Occup Environ Health 2009;82:1023-30.

25. Sacker A, Head J, Gimeno D, Bartley M. Social Inequality in Physical and Mental Health Comorbidity Dynamics. Psychosom Med 2009.

26. Re-integratie - van bijstand naar werk. Rekenkamer Amsterdam 2007. 
Figure 1: Flow of participants and response at baseline and follow-up. 
Figure 2: Health at baseline and follow-up for subjects who continued to be unemployed $(n=918)$ and subjects who re-entered paid employment $(n=47)$ during the follow up period of six months. 


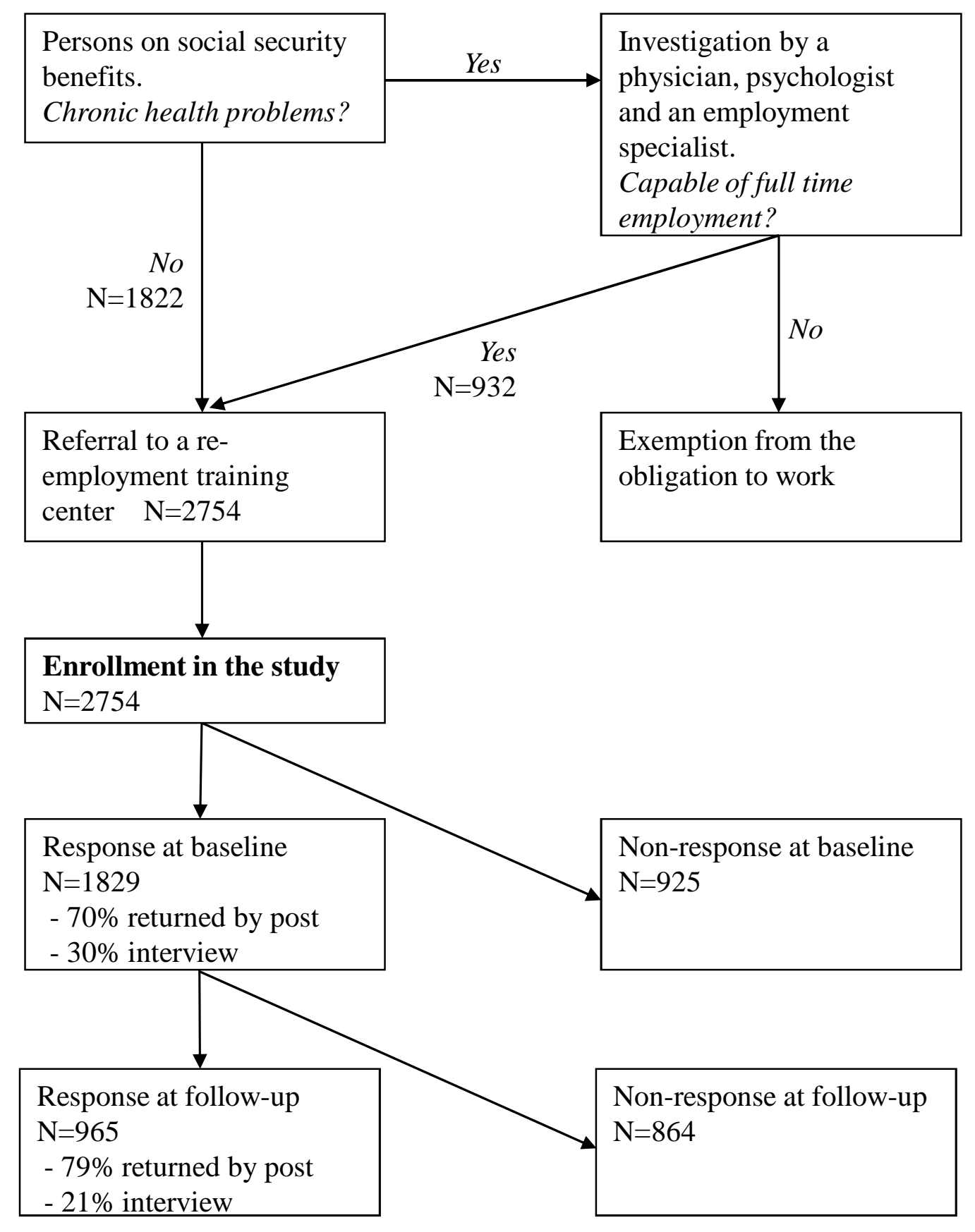




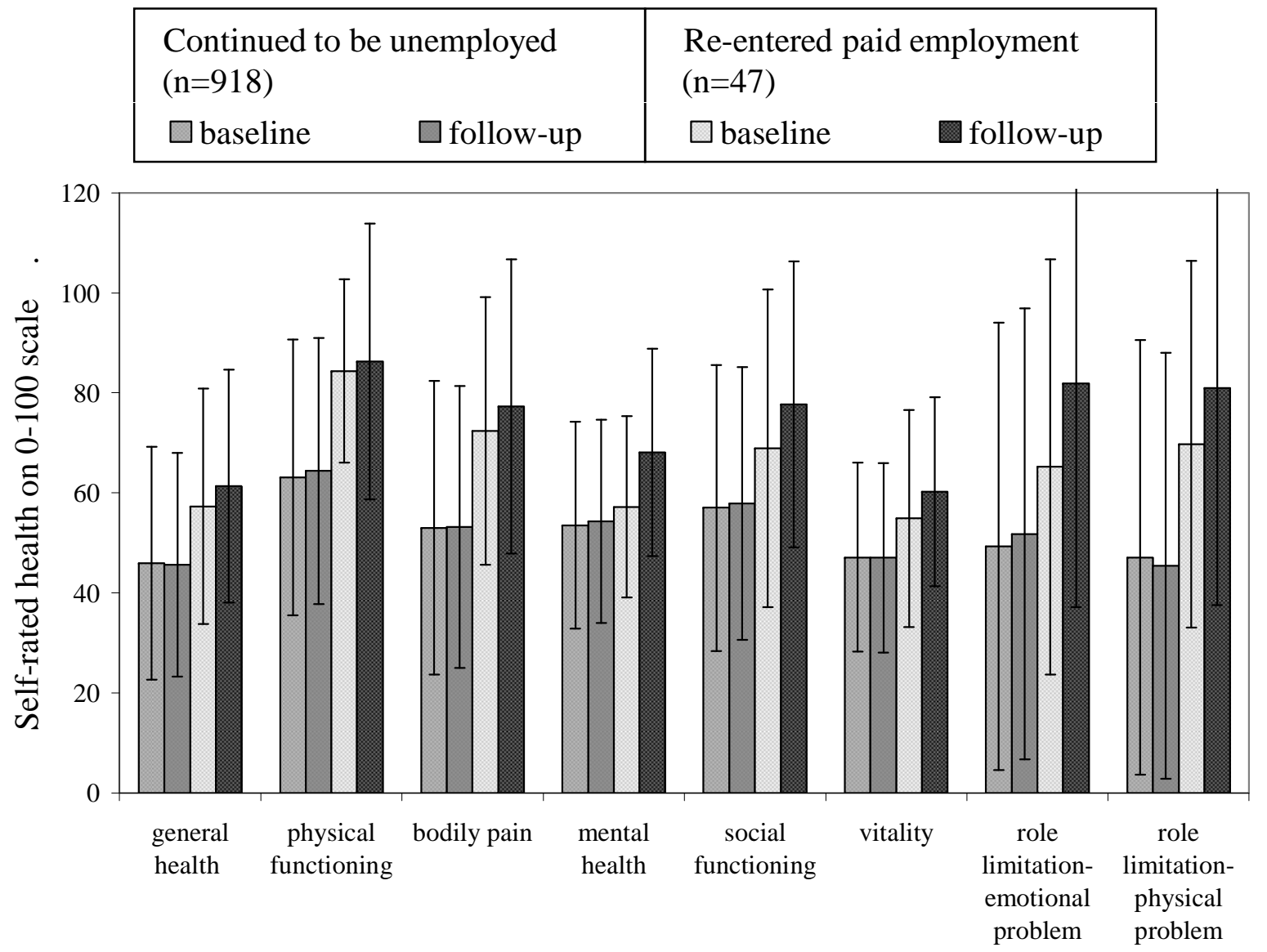

